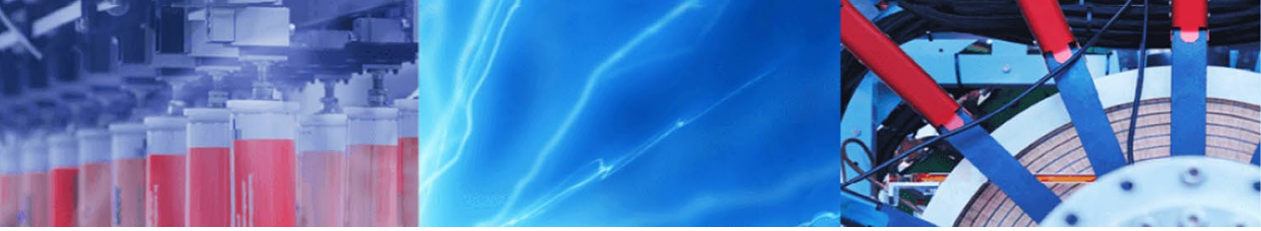

Research Article

\title{
Computational screening of zeolites for the adsorption of selected pharmaceutical pollutants
}

\author{
Fred Sifuna Wanyonyi ${ }^{1} \cdot$ Anthony Pembere $^{2} \cdot$ Gershom Kyalo Mutua ${ }^{1} \cdot$ Francis Orata $^{1} \cdot$ Hitler Louis $^{3}$
}

Received: 28 August 2020 / Accepted: 13 October 2020 / Published online: 27 October 2020

(c) Springer Nature Switzerland AG 2020

\begin{abstract}
Molecular simulations have been used as a screening tool to identify promising zeolites for the removal of selected pharmaceutical pollutants. 40 zeolites with different structural and chemical configurations were studied. Galophosphate cloverite (CLO) of the chemical formula, $\mathrm{F}_{24} \mathrm{Ga}_{96} \mathrm{P}_{96} \mathrm{O}_{372}(\mathrm{OH})_{24}$, with pores of 20 rings and the lowest observed bulk density, showed exceptionally preferred adsorption of diclofenac [2-(2,6-dichlorophenyl)amino benzeneacetic acid), ciprofloxacin [1,3,7-Trimethylpurine- 2,6-dione] and chloramphenicol [2,2-dichloro-N-[(IR,2IR)-1, 3-dihydroxy-1-(4-nitrophenyl) propan-2-yl acetamide]. This selectivity was attributed to the geometry and structural composition of the cavities. We also investigated the most stable adsorbed compositions of the pollutants in the CLO zeolite. Our calculations show that diclofenac, ciprofloxacin and chloramphenicol molecules are adsorbed into the pores with adsorption energies of $-78.23,-173.68$ and $-84.46 \mathrm{kcal} / \mathrm{mol}$ respectively. Additional calculations were also made to obtain detailed information on desorbed products. It is seen that dechlorination is the most energetically preferred process compared to dehydrogenation and dehydroxylation.
\end{abstract}

Keywords Monte Carlo simulation · Adsorption isotherms · Pharmaceutical pollutants · Zeolites

\section{Introduction}

Pharmaceutical drugs are widely used in health care, injecting a large number into the environment in unused or metabolized form [1]. Their presence in the aquatic environment is considered a potential toxicological hazard because they pose long-term risk to aquatic organisms and their dependents through endocrine destruction and the development of drug-resistant bacterial strains [2]. Traditional sewage treatment plants are not designed to remove these contaminants effectively [3], so alternative water treatment methods are still needed. Adsorption removal is one of the most promising techniques due to its efficiency [4]. Zeolites are interesting candidates because of their unique adsorption properties. They exhibit interesting properties such as adsorption, cation exchange, molecular sieving, and catalysis [5-7]. Zeolites have the basic structure which consists of tetrahedron having four oxygen atoms surrounding aluminum and silicon atoms. The framework is usually negatively charged, balanced by exchangeable cations such as $\mathrm{K}^{+}, \mathrm{Na}^{+}, \mathrm{Mg}^{2+}$ and $\mathrm{Ca}^{2+}$ [8]. Modification of zeolites can be done in different ways, whereby silicon can be replaced with other metal atoms, like germanium, aluminum, iron, boron etc. These changes

Electronic supplementary material The online version of this article (https://doi.org/10.1007/s42452-020-03694-y) contains supplementary material, which is available to authorized users.

$\triangle$ Anthony Pembere, apembere@jouust.ac.ke| ${ }^{1}$ Department of Pure and Applied Chemistry, Masinde Muliro University of Science and Technology, P.O. Box 190, 50100 Kakamega, Kenya. ${ }^{2}$ Department of Physical Sciences, Jaramogi Oginga Odinga University of Science and Technology, P.O. Box 210, 40601 Bondo, Kenya. ${ }^{3}$ Computational Quantum Chemistry Research Group, Department of Pure and Applied Chemistry, Faculty of Physical Sciences, University of Calabar, Calabar 1115, Nigeria. 
can have a significant effect on the properties of the zeolite involved in adsorption and catalysis processes.

To date, most of the zeolite materials that have been investigated for the separation of organic compound mixtures belong to the MFI-type, [9-15] although others like Mordenite (MOR), [16] Linde Type A (LTA), [17, 18] Faujasite (FAU), [19-21] Deca-dodecasil 3R (DD3R), [22] chabazite (CHA) $[23,24]$ and Silicoaluminophosphate (SAPO), [23, 25] have also been studied. For example, Rossner et al. [26] investigated the removal of 25 organic pollutants from spiked lake water by mordenite (MOR topology) and zeolite Y (FAU topology), whereby modernite showed promising results for quantitative removal of various compounds, whereas zeolite Y removed only one pharmaceutical (fluoxetine). Some experimental studies followed Rosner et al.'s work in assessing the performance of high silica zeolite in the removal of drugs and related contaminants [27-29]. For example, 15 pharmaceuticals were investigated on high-silica mordenite by De Ridder et al. [29] A few other studies for pharmaceutical adsorption employing highsilica zeolites have been done by Braschi, Martucci et al. [28]. Currently, molecular simulations play an essential role in enhancing our understanding of the properties of closed molecular fluids in zeolites [30-32]. It is difficult to do experiments that give us molecular level insights as most of the activity occurs inside the zeolite material. To get information of the processes inside the cavities, it is important to comprehend adsorption of the reactants, diffusion and then chemical transformation at the active sites. The reaction rate and the products formed can be affected by each step. Thus, the experimental efforts can be nicely complemented by the molecular simulations $[33,34]$. Although computational chemistry methods are widely used in zeolite science, computational investigations of drug adsorption in zeolite are rare [35]. Force-field based Monte Carlo (MC) simulations have been used to study the adsorption of organic molecules in all-silica zeolites for various species, like aromatics [36], organic structure-directing agents (OSDAs) [37], and glucose [38]. In contrast to this, force field methods have rarely been used to study the interaction of pharmaceuticals with zeolites and the molecular dynamics (MD) investigation of salbutamol and theophylline diffusion in zeolite BETA by Fatouros et al. [39] is a rare example. While a similar MDbased approach was later used by Spanakis et al. [40] and Fischer [26], on two all-silica zeolites, it is noteworthy that modelling techniques have not been employed to investigate the adsorption of pharmaceuticals in a large variety of zeolites, aiming at applications in either drug delivery or wastewater treatment. This work aims at establishing weather molecular simulation approach can be used for an approximate prediction of pharmaceutical pollutant removal efficiency on a large variety of zeolites i.e; CLO,
SBT, MFI, SBE, FAU, TSC, PAR, ITE, CGF, RTH, RUT, DOH, MTF, THO, CZP, AHT, MON, EUO, SAO, SFE, OSI, LTN, MTN, STO, AEL, FRE, MOR, DDR, WEI, SBS, MSO, HEU, KFI, LTA, NAT, RHO, ESV, SAT, BOG and NON [41]. This study focuses on diclofenac, ciprofloxacin and chloramphenicol pharmaceuticals. Diclofenac is the mostly used non-steroidal anti-inflammatory drug used to reduce inflammation and also as a painkiller for the relief of mild to moderate pain associated with head ache, backache and postoperative pain, $[33,42]$ while ciprofloxacin and chloramphenicol are broad-spectrum antibiotics. The focus on the three pharmaceutical drugs is motivated by the fact that they are largely consumed [43] resulting in their detection in surface water and sewage treatment plants effluents [43].

\section{Computational models and methods}

The molecular mechanical methods are based on classical mechanics. These methods allow the study of materials at atomic level and determine the bulk properties through force fields, which are a set of potential functions and parameters. The potential functions define the interactions in a molecular system. These functions can be parameterised in a variety of analytical forms to give the correct energies and forces. The parameters encompass optimal values of balance, such as distances, bond angles and force constants. In the force field based approach, the molecules are represented as a set of spheres of different sizes and masses, connected by springs of different lengths and spring continuously. The atoms interact through a series of forces like bond stretching, bond bend and dihedral torsion, and through interactions between non-bonded atoms such as van der Waals and electrostatic interactions. Those forces can be written in term of potential energy functions. To define the zeolite structure by molecular mechanics, most simulation studies are performed using the method proposed by Kiselev et al. [44]. According to the model by Kiselev et al. [44], the zeolite framework is kept rigid and the non-framework molecules are allowed to move freely in the zeolite.

The Monte Carlo (MC) method was used in this study. To generate a set of configurations according to a Markovian stochastic process, the algorithm by Teller et al. [45] is used. The strength of the MC method lies in its capability to calculate statistical averages without explicitly sampling the entire partition function. The capability to deal with complex variation in spatial and energetic variables is what makes MC such an attractive method. To study the adsorption properties, the grand-canonical ensemble is a natural choice. For each zeolite, we conducted a single GCMC simulation for the pharmaceuticals at $298 \mathrm{~K}$ in order to screen the structures exhibiting 
the most interesting adsorption properties. For the selected structures whole adsorption isotherms were calculated. The adsorption isotherm measures the number of adsorbed molecules as a function of the chemical potential (pressure) of the fluid that is in contact with the porous material at a given temperature, T. An adsorption isotherm is conveniently computed in the grand canonical ensemble in which the temperature, volume $(\mathrm{V})$, and chemical potential of the adsorbed component $(\mu)$ are imposed. For the grand-canonical ensemble the partition function reads [35] (Eq. 1);

$Q_{\mu, V, T}=\sum_{N=0}^{\infty} \frac{\exp (\beta \mu N) V^{N}}{\Lambda^{3 N} N !} \int d s^{N} \exp \left[-\beta U\left(r^{N}\right)\right]$

The connection with the thermodynamics is made via the grand-potential $\Omega$, which is related to the partition function via (Eq. 2);

$\beta \Omega=-\ln Q_{\mu, v, T}$

In this ensemble, the number of adsorbed molecules $(N / V)$ is an ensemble average (Eq. 3 );

$\frac{N}{V}=\frac{1}{Q_{\mu, V, T}} \sum_{N=0}^{\infty} \frac{N}{V} \frac{\exp (\beta \mu N) V^{N}}{\Lambda^{3 N} N !} \int d s^{N} \exp \left[-\beta U\left(r^{N}\right)\right]$

We also explored the most stable adsorbed configurations of the pharmaceuticals on the zeolites using the simulated annealing approach [46], as embedded in the material studio adsorption locator module. The zeolite structures were extracted from the IZA structure database [41], and then optimized using material studio Forcite module [47]. The DREIDING force field (Material Studio Forcite module) [47], has been previously used with success in the theoretical investigation of organic structure directing agents interacting with zeolites [37]. Thus, it can be expected that this force field can represent the interaction between organic molecules and zeolites. In the simulations, rigid zeolite models were used and guest-guest interactions were ignored. Openly available data repository, PubChem [48] was the source for the molecular structures of the pharmaceutical contaminants. They were then imported into the Biovia Materials Studio 2017 software [49]. Geometry optimization and frontier molecular orbital analysis of the pharmaceuticals was done using $\mathrm{DMol}^{3}$ method [50,51], prior to Monte Carlo simulations. For the following discussion, we report on the results obtained using the generalized gradient approximation (LDA) with the PDW exchange-correlation functional [52] and the double-numerical basis set [50] while the energies calculated at GGA/PW91, B3LYP, GGA/BLYP, m-GGA/MO6-L, m-GGA/M11-L, LDA/PWC and GGA/HCTH levels of theory are also listed in S2 (supporting information).

\section{Results and discussion}

We first plotted the frontier orbitals and the optimized structures of diclofenac, ciprofloxacin and chloramphenicol as seen in Fig. 1. The HOMO orbital energy $\left(E_{\text {номо }}\right)$ is normally related to the electron-donating ability of a molecule whereas LUMO orbital energy $\left(E_{\text {LUMO }}\right)$ is associated with the electron-accepting ability of a molecule from which the global hardness $(\eta)$ can be calculated. The energy gap between HOMO and LUMO also helps to describe the chemical behavior and electrical properties of molecules, with lower energies indicating higher reactivity and lower stability. It can be observed that the HOMO of diclofenac is concentrated on benzene ring and around $\mathrm{N}-$ and $\mathrm{OH}$ - groups, similar to the LUMO but less pronounced. In ciprofloxacin the HOMO is localized on lower side on dinitro-phenyl ring, while the LUMO on the upper phenyl ring having nitrogen in the ring extending to $\mathrm{OH}$ group and $\mathrm{O}^{-}$, which are attached to the phenyl ring. For chloramphenicol, the HOMO is also on lower part of the molecule and appears around the benzene ring, $\mathrm{OH}$ group and the acetamide group in which $\delta$-interaction bonding system is on semicircle of the ring, while the LUMO is localized on nitro-phenyl ring.

The calculations of the energy levels of the electron orbitals allowed quantifying the value of the HOMO and LUMO energies, whereby diclofenac has the lowest HOMO energy $(-4.64 \mathrm{eV})$ while chloramphenicol has a relatively higher HOMO energy $(-1.92 \mathrm{eV})$. Previous studies have established that the larger the HOMO-LUMO energy gap, the harder and more stable/less reactive the molecule $[53,54]$. It is seen that diclofenac has a relatively higher chemical hardness of $1.36 \mathrm{eV}$ (Table 1), compared to that of chloramphenicol and ciprofloxacin, implying that diclofenac has a higher stability. On the contrary, chloramphenicol and ciprofloxacin molecules with a relatively smaller LUMO-HOMO gap, are termed as "soft". In terms of chemical change, "softer" molecules are more reactive than "harder" ones. Based on this, we initially screened the adsorption of diclofenac on the forty zeolites. The adsorption isotherms are shown in Figures S1-S40 (supporting information). According to Giles and co-workers, [55] adsorption isotherms are classified into the four groups. The first group is the C-shaped adsorption isotherm which describes a linear increase of the pollutants adsorption loading with the equilibrium concentration of pollutant in solution. The second category is the L-shaped isotherm that occurs when the adsorbent has a limited number of adsorption sites, leading to the appearance of a plateau in the adsorption isotherm after a specific equilibrium concentration of pollutants, suggesting the saturation of the 
Fig. 1 a Optimized structures of ciprofloxacin, diclofenac and chloramphenicol. $\mathbf{b}$ Frontier molecular orbitals of ciprofloxacin, diclofenac and chloramphenicol. Atoms in grey, red, white, green, blue color represent Carbon, Oxygen, Hydrogen, Chlorine and Nitrogen respectively. Yellow and blue regions correspond to positive and negative values of the orbital (a)

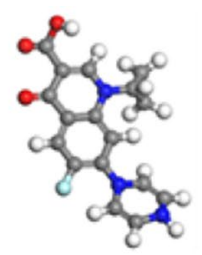

Ciprofloxacin

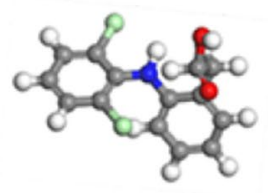

Diclofenac

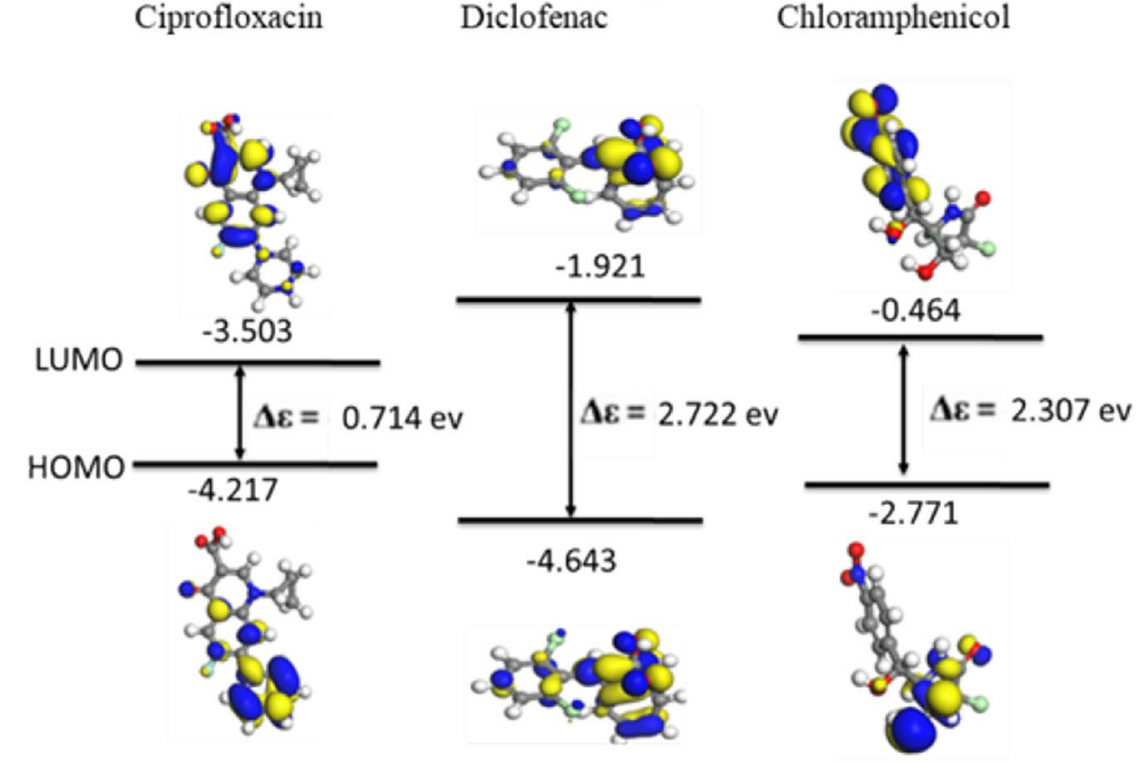

(b)
Table 1 Key quantum chemical descriptors obtained for the three pharmaceutical products

\begin{tabular}{llll}
\hline Pharmaceuticals & $\begin{array}{l}\text { Chemical } \\
\text { potential (eV) }\end{array}$ & $\begin{array}{l}\text { Chemical } \\
\text { hardness }(\mathrm{eV})\end{array}$ & $\begin{array}{l}\text { Chemical } \\
\text { softness } \\
(\mathrm{eV})\end{array}$ \\
\hline Diclofenac & -3.28 & 1.36 & 0.74 \\
Ciprofloxacin & -3.86 & 0.36 & 2.80 \\
Chloramphenicol & -1.62 & 1.15 & 0.87 \\
\hline
\end{tabular}

adsorbent. Thirdly, the $\mathrm{H}$-shaped isotherms that indicate that the adsorbent have a higher affinity for OMPs, and lastly, the $\mathrm{S}$-shape that is attributed to a higher attraction between the pollutants at the surface of the adsorbent. Among the various zeolites tested, it was observed that only CLO exhibited the L-shape isotherm with an almost maximum loading and a pronounced inflection at a maximum loading of $60 \mathrm{~mol}$ per unit cell (Fig. 1 and S41). Conversely, all the other zeolites exhibited low loading. For example, the MFI zeolite (family of high silica zeolites, a medium pore zeolite, featuring a 10-ring pore opening with a diameter of approximately $5.5 \AA$ and a chemical formulae $\mathrm{Al}_{27} \mathrm{Si}_{69} \mathrm{O}_{165}$ ), showed no loading as seen in Fig. 1 (more details are shown in Fig. S42), due to its narrow channel openings [56] and as a result the cations tend to be located in the intersections, blocking the favorable adsorption sites. Also, the SBT (with a 12-ring pore, $7.2 \times 7.4 \mathrm{~nm}$ in diameter), SBE (12-ring pore), FAU (3-dimensional channel system with large pore openings formed by 12 rings, $7.4 \times 7.4 \mathrm{~nm}$ in diameter) and TSC (8-ring pores, $4.2 \times 4.2 \mathrm{~nm}$ in diameter) type of zeolites with chemical formulae $\mathrm{Ga}_{36} \mathrm{Zn}_{36} \mathrm{P}_{72} \mathrm{O}_{288}$, $\mathrm{Al}_{32} \mathrm{CO}_{32} \mathrm{P}_{64} \mathrm{O}_{256}, \mathrm{Al}_{58} \mathrm{Si}_{134} \mathrm{O}_{384}$ and $\mathrm{Al}_{192} \mathrm{Si}_{192} \mathrm{O}_{768}$ respectively, exhibited low loading of 3, 5, 8 and 12 mol (Fig. 1) of diclofenac per unit cell, respectively (more details are shown in Figs. S41-S46). The adsorption is minimal when the size of diclofenac is larger than the pore opening size of zeolite. Zeolites would then behave as molecular sieves [57]. Sorption fields of diclofenac on several representative zeolites are also shown in Fig. S56 (supporting information). It is seen that CLO has more sorption fields for diclofenac compared to other zeolites. It is clear from Fig. S56 that the diclofenac molecule prefers to locate at the intersections in CLO zeolite structure. Since these intersections have a maximum capacity of $60 \mathrm{~mol}$ per cell, an excess loading of four molecules per cell can only be achieved by "pushing" diclofenac into the straight and zigzag channels. The simulation results indicate that CLO is a promising adsorbent for the removal of diclofenac and it demonstrates that the very good packing of diclofenac is directly related to the probability of crossing and bending at the intersections of CLO (Fig. 2).

The most stable adsorbed configurations of the pharmaceuticals in the CLO zeolite alongside the corresponding adsorption energies was also probed as seen in Fig. 3A. Diclofenac molecule was observed to be located at the 


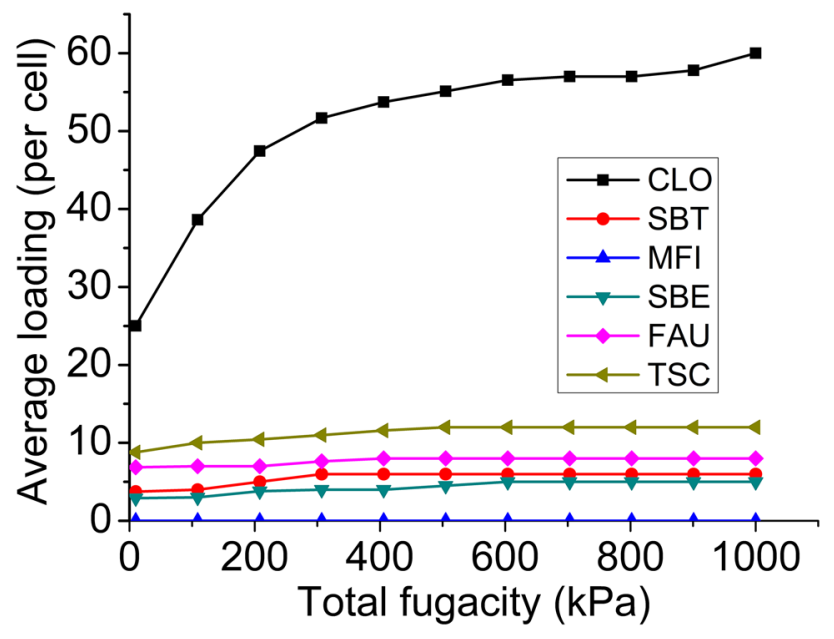

Fig. 2 Adsorption isotherms of diclofenac on various zeolites at $298 \mathrm{~K}$

centre of the 20 ring channel, facing the direction of the channel, while the phenyl group directly lie on the phenyl ring. This can be an indication that the reaction takes place inside the zeolite. Adsorption energy of $-78.23 \mathrm{kcal} / \mathrm{mol}$ was observed for the most stable configuration. On the other hand, Fig. 3B shows the calculated Gibbs free energy of formation of various products relative to diclofenac in CLO. Differences in the Gibbs free energy of formation determine the equilibrium concentration of the various reaction intermediates [58]. If we use the free energies of formation [59], we can predict the various contributing routes and the possible products that can form. For example, the Gibbs free energy of formation for the removal of chlorine from diclofenac is smaller $(16.38 \mathrm{kcal} / \mathrm{mol}$ compared to dehydrogenation $(140.95 \mathrm{kcal} / \mathrm{mol})$ and dehydroxylation $(101.48 \mathrm{kcal} / \mathrm{mol})$. Thus the formation of the later products is likely to be suppressed.

We also studied the adsorption behavior of ciprofloxacin on several representative zeolites. Figure 4, shows

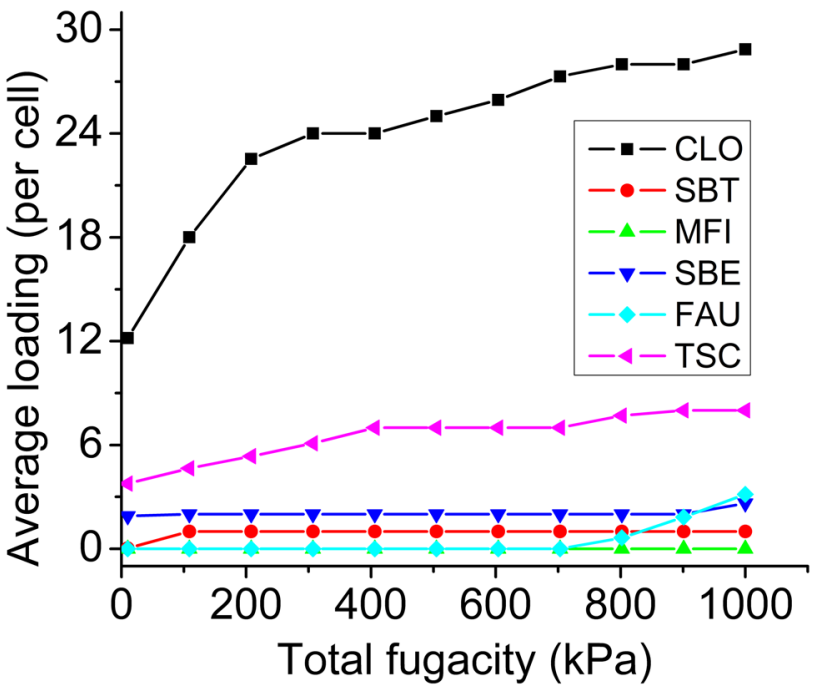

Fig. 4 Adsorption isotherms of ciprofloxacin on various zeolites at $298 \mathrm{~K}$

the adsorption isotherms for ciprofloxacin on CLO, SBT, MFI, SBE, FAU and TSC zeolites (more details are shown in Figs. S47-S50, supporting information). Among the various zeolites, only CLO exhibited the L-shape isotherm with maximum loading and a pronounced inflection at a maximum loading of $29 \mathrm{~mol}$ of ciprofloxacin per unit cell which is less compared to sorption of diclofenac. It is also seen that MFI showed zero loading. The SBT, SBE, FAU and TSC exhibited low loading of 1, 3, 4 and $8 \mathrm{~mol}$ of ciprofloxacin per unit cell. Additionally, CLO has more sorption fields compared to SBT, SBE, FAU and TSC (Fig. S57). Figure $5 \mathrm{~A}$, visualizes the lowest-energy configuration of ciprofloxacin in the CLO structure. The central part of the molecule occupies a 20-ring window connecting two super cages, while the phenyl moieties and the side chain are located to the side assemblies of the 20-rings bordering these cages of the 8 rings. This can be an indication that the reaction takes place inside the zeolite. The most
Fig. 3 A Structures of the most stable configuration of diclofenac adsorbed on the CLO. B The calculated Gibbs free energy of formation of various products relative to diclofenac in CLO. Energies are in $\mathrm{kcal} / \mathrm{mol}$
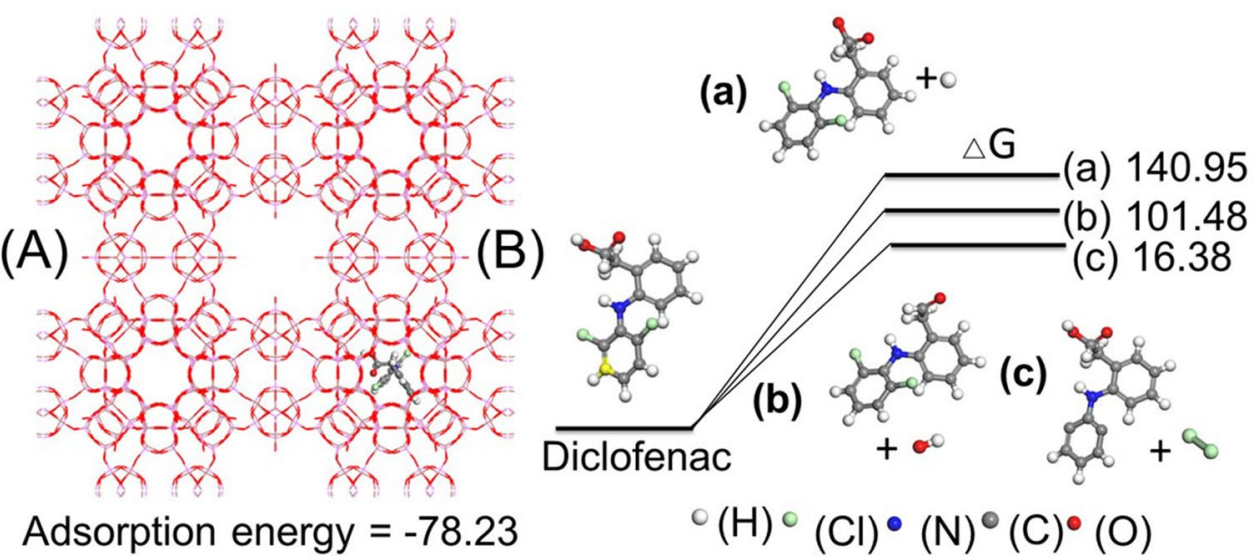
Fig. 5 A Structures of the most stable configuration of ciprofloxacin adsorbed on the CLO. B The calculated Gibbs free energy of formation of various products relative to ciprofloxacin in CLO. Energies are in $\mathrm{kcal} / \mathrm{mol}$

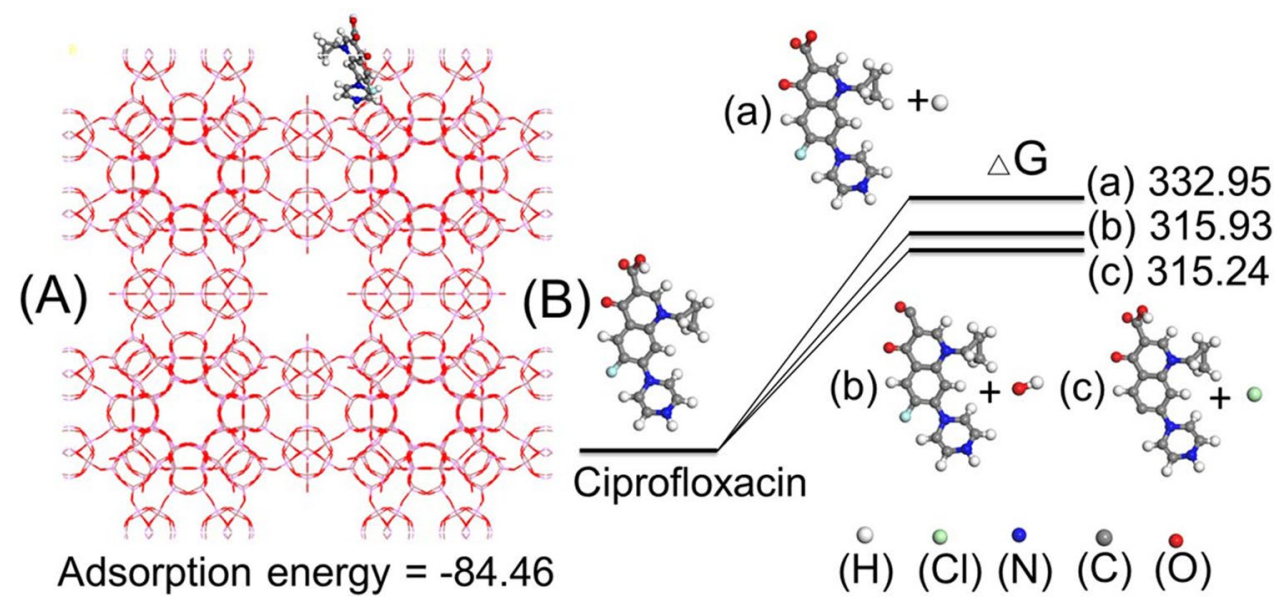

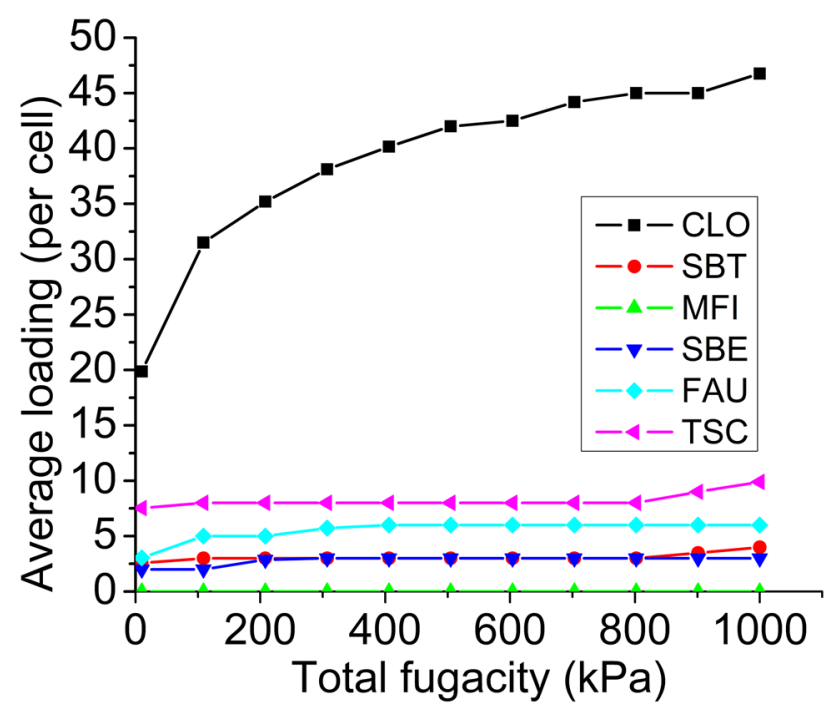

Fig. 6 Adsorption isotherms of chloramphenical on various zeolites at $298 \mathrm{~K}$ stable configuration energy of ciprofloxacin gave absorption energy of $-84.46 \mathrm{kcal} / \mathrm{mol}$ which is lower than that of diclofenac. Figure 5B shows the calculated Gibbs free energy of formation of various products relative to ciprofloxacin in CLO. It is seen that the Gibbs free energy of formation for the removal of chlorine from ciprofloxacin is smaller $(315.24 \mathrm{kcal} / \mathrm{mol})$ compared to dehydrogenation $(332.95 \mathrm{kcal} / \mathrm{mol})$ and dehydroxylation $(315.93 \mathrm{kcal} /$ $\mathrm{mol}$ ). Thus the formation of the later products is likely to be suppressed.

Figure 6 shows the adsorption isotherms of chloramphenicol on the CLO, SBT, MFI, SBE, FAU and TSC representative zeolites (more details are shown in Figs. S51-S55, supporting information). Just like for diclofenac and ciprofloxacin, it is only CLO that exhibited the L-shape isotherm with maximum loading and a pronounced inflection at a maximum loading of $48 \mathrm{~mol}$ of chloramphenicol per unit cell. It is interesting to note that diclofenac sorption on the CLO is higher compared to the ciprofloxacin and
Fig. 7 A Structures of the most stable configuration of chloramphenicol adsorbed on the CLO. B The calculated Gibbs free energy of formation of various products relative to chloramphenicol in CLO. Energies are in $\mathrm{kcal} / \mathrm{mol}$

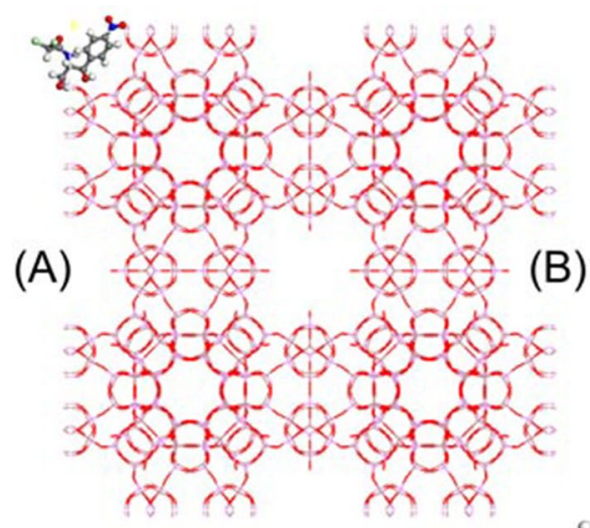

(B)

Adsorption energy $=-173.68 \quad(\mathrm{H})(\stackrel{\circ}{\mathrm{Cl}})(\stackrel{\circ}{\mathrm{N}}) \quad \stackrel{\circ}{(\mathrm{C})}(\stackrel{\circ}{\mathrm{O}})$ (a)
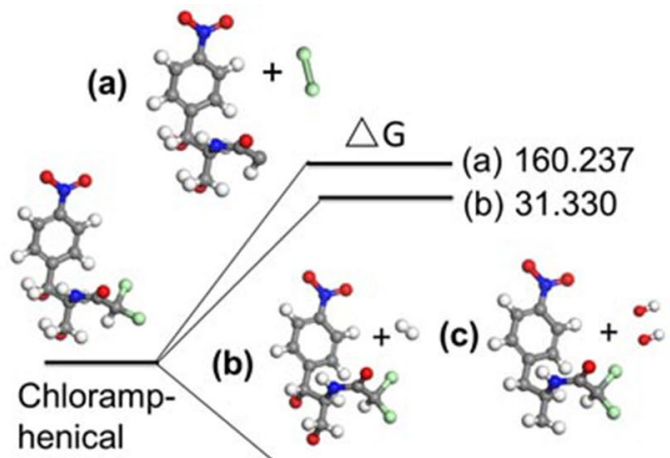

(c) -105.016 
chloramphenicol. It is also seen that just like sorption of diclofenac and ciprofloxacin, chloramphenicol showed zero loading on MFI. The SBT, SBE, FAU and TSC exhibited low loading of 4, 3, 6 and 10 mol of chloramphenicol per unit cell, respectively. It is also seen that CLO has more sorption fields for chloramphenicol compared to SBT, SBE, FAU and TSC (Fig. S58).

On the other hand, Fig. 7A, shows structures of the most stable configuration of chloramphenicol adsorbed on the CLO. The conformation of chloramphenicol adsorbed in CLO is very similar to that of the free molecule just like ciprofloxacin. The central part of the molecule occupies a 20-ring window connecting super cages, and both phenyl moieties with the side chain are located to the upper and down assemblies of 20-rings bordering these cages. The most stable configuration gave adsorption energy of $-173.23 \mathrm{kcal} / \mathrm{mol}$ which is two folds lower than that of diclofenac and ciprofloxacin. Figure $3 \mathrm{~B}$ shows the calculated Gibbs free energy of formation of various products relative to chloramphenicol in CLO. It is seen that the Gibbs free energy of formation for the removal of chlorine is smaller $(-105.01 \mathrm{kcal} / \mathrm{mol})$ compared to dehydrogenation $(31.33 \mathrm{kcal} / \mathrm{mol})$ and dehydroxylation $(160.23 \mathrm{kcal} /$ $\mathrm{mol})$. Hence the formation of the later products is likely to be suppressed.

\section{Conclusion}

According to the molecular simulation results in this research, CLO zeolite has proved to be the satisfactory zeolite suited for adsorption of diclofenac, ciprofloxacin and chloramphenicol, since its structure has more adsorption sites. The simulations using a universal force field yielded rather unsatisfactory results for the adsorption isotherms of diclofenac, ciprofloxacin and chloramphenicol in other zeolites as it showed low loading. The most stable adsorbed configurations of the adsorbed pollutants on the CLO zeolite was also probed, whereby diclofenac, ciprofloxacin and chloramphenicol molecules get adsorbed at the pores with reasonably high adsorption energies $(-78.23,-173.68$ and $-84.46 \mathrm{kcal} / \mathrm{mol}$ for diclofenac, chloramphenicol and ciprofloxacin respectively). The larger adsorption energy at the pores appears due to the strong electrostatic interactions between the symmetric, electron-rich pore. Thus these simulations have proven to be very useful for the initial screening of adsorbents, prior to experimental work. This screening has considerable potential that can lead to the development of new remediation techniques for wastewater treatment.
Acknowledgements The Department of Pure and Applied Chemistry, Masinde Muliro University of science and Technology is acknowledgement.

\section{Compliance with ethical standards}

Conflict of interest The authors declare that they have no known competing financial interests or personal relationships that could have appeared to influence the work reported in this paper.

\section{References}

1. Akhtar J, Amin NAS, Shahzad K (2016) A review on removal of pharmaceuticals from water by adsorption. Desalin Water Treat 57:12842-12860

2. Tambosi JL, Yamanaka LY, José HJ, Moreira RDFPM, Schröder HF (2010) Recent research data on the removal of pharmaceuticals from sewage treatment plants (STP). Quim Nova 33:411-420

3. Orata $F(2020)$ Chemicals of emerging concern in surface and wastewater: a perspective of their fate within the lake victoria catchment area of Kenya. In: Effects of emerging chemical contaminants on water resources and environmental health. IGI Global, pp 1-16

4. Shikuku VO, Zanella R, Kowenje CO, Donato FF, Bandeira NM, Prestes OD (2018) Single and binary adsorption of sulfonamide antibiotics onto iron-modified clay: linear and nonlinear isotherms, kinetics, thermodynamics, and mechanistic studies. Appl Water Sci 8:175

5. Shikuku VO, Donato FF, Kowenje CO, Zanella R, Prestes OD (2015) A comparison of adsorption equilibrium, kinetics and thermodynamics of aqueous phase clomazone between Faujasite $X$ and a natural zeolite from Kenya. S Afr J Chem 68:245-252

6. Pham T, Lee B, Kim J (2016) Novel improvement of $\mathrm{CO}_{2}$ adsorption capacity and selectivity by ethylenediamine-modified nano zeolite. J Taiwan Inst Chem Eng 66:239-248

7. Ennaert T, Van Aelst J, Dijkmans J, De Clercq R, Schutyser W, Dusselier M, Verboekend D, Sels BF (2016) Potential and challenges of zeolite chemistry in the catalytic conversion of biomass. Chem Soc Rev 45:584-611

8. Russo AV, Andrade CV, De Angelis LE, Jacobo SE (2018) Adsorption and catalytic oxidation of organic pollutants using Fe-Zeolite. Water Sci Technol 77:939-947

9. Bernal M, Coronas J, Menendez M, Santamaria J (2004) Separation of $\mathrm{CO}_{2} / \mathrm{N}_{2}$ mixtures using Mfi-type zeolite membranes. AIChE J 50:127-135

10. Gardner TQ, Falconer JL, Noble RD (2002) Adsorption and diffusion properties of zeolite membranes by transient permeation. Desalination 149:435-440

11. Harlick P, Tezel F (2003) Adsorption of carbon dioxide, methane and nitrogen: pure and binary mixture adsorption for ZSM-5 with $\mathrm{SiO}_{2} / \mathrm{Al}_{2} \mathrm{O}_{3}$ ratio of 280. Sep Purif Technol 33:199-210

12. Makrodimitris K, Papadopoulos GK, Theodorou DN (2001) Prediction of permeation properties of $\mathrm{CO}_{2}$ and $\mathrm{N}_{2}$ through Silicalite via molecular simulations. J Phys Chem B 105:777-788

13. Poshusta JC, Tuan VA, Falconer JL, Noble RD (1998) Synthesis and permeation properties of sapo-34 tubular membranes. Ind Eng Chem Res 37:3924-3929

14. Van den Broeke L, Bakker W, Kapteijn F, Moulijn J (1999) Transport and separation properties of a Silicalite- 1 membrane-I. Operating conditions. Chem Eng Sci 54:245-258

15. Yu JJ, Jiang Z, Zhu L, Hao ZP, Xu ZP (2006) Adsorption/desorption studies of $\mathrm{NO}_{\mathrm{x}}$ on well-mixed oxides derived from 
Co-Mg/Al hydrotalcite-like compounds. J Phys Chem B 110:4291-4300

16. Delgado JA, Uguina MA, Gómez JM, Ortega L (2006) Adsorption equilibrium of carbon dioxide, methane and nitrogen onto $\mathrm{Na}$-and $\mathrm{H}$-mordenite at high pressures. Sep Purif Technol 48:223-228

17. Goj A, Sholl DS, Akten ED, Kohen D (2002) Atomistic simulations of $\mathrm{CO}_{2}$ and $\mathrm{N}_{2}$ adsorption in Silica zeolites: the impact of pore size and shape. J Phys Chem B 106:8367-8375

18. Nam GM, Jeong BM, Kang SH, Lee BK, Choi DK (2005) Equilibrium isotherms of $\mathrm{CH} 4, \mathrm{C}_{2} \mathrm{H}_{6}, \mathrm{C}_{2} \mathrm{H}_{4}, \mathrm{~N}_{2}$, and $\mathrm{H}_{2}$ on Zeolite $5 \mathrm{~A}$ using a static volumetric method. J Chem Eng Data 50:72-76

19. Hasegawa Y, Kusakabe K, Morooka S (2001) Effect of temperature on the gas permeation properties of Nay-type zeolite formed on the inner surface of a porous support tube. Chem Eng Sci 56:4273-4281

20. Jia W, Murad S (2004) Molecular dynamics simulations of gas separations using Faujasite-type zeolite membranes. J Chem Phys 120:4877-4885

21. Kusakabe K, Kuroda T, Uchino K, Hasegawa Y, Morooka S (1999) Gas permeation properties of ion-exchanged Faujasite-type zeolite membranes. AIChE J 45:1220-1226

22. Himeno S, Tomita T, Suzuki K, Yoshida S (2007) Characterization and selectivity for methane and carbon dioxide adsorption on the all-Silica DD3R zeolite. Microporous Mesoporous Mater 98:62-69

23. García-Pérez E, Parra J, Ania C, García-Sánchez A, Van Baten J, Krishna R, Dubbeldam D, Calero S (2007) A computational study of $\mathrm{CO}_{2}, \mathrm{~N}_{2}$, and $\mathrm{CH}_{4}$ adsorption in zeolites. Adsorption 13:469-476

24. Krishna R, Van Baten J (2008) Insights into diffusion of gases in zeolites gained from molecular dynamics simulations. Microporous Mesoporous Mater 109:91-108

25. Li S, Alvarado G, Noble RD (2005) Falconer JL (2005) Effects of Impurities on $\mathrm{CO}_{2} / \mathrm{CH}_{4}$ Separations through Sapo-34 membranes. J Membr Sci 251:59-66

26. Rossner A, Snyder SA, Knappe DR (2009) Removal of emerging contaminants of concern by alternative adsorbents. Water Res 43:3787-3796

27. Fukahori S, Fujiwara T, Ito R, Funamizu N (2011) Ph-dependent adsorption of sulfa drugs on high silica zeolite: modeling and kinetic study. Desalination 275:237-242

28. Braschi I, Blasioli S, Gigli L, Gessa CE, Alberti A, Martucci A (2010) Removal of sulfonamide antibiotics from water: evidence of adsorption into an organophilic zeolite $Y$ by its structural modifications. J Hazard Mater 178:218-225

29. De Ridder DJ, Verberk J, Heijman SG, Amy GL, Van-Dijk JC (2012) Zeolites for nitrosamine and pharmaceutical removal from demineralised and surface water: mechanisms and efficacy. Sep Purif Technol 89:71-77

30. AuerbachSM Carrado KA, Dutta PK (2003) Handbook of zeolite science and technology. CRC Press, Boca Raton

31. Dubbeldam D, Calero S, Maesen TL, Smit B (2003) Incommensurate diffusion in confined systems. Phys Rev Lett 90:245-901

32. Maesen TL, Beerdsen E, Calero S, Dubbeldam D, Smit B (2006) Understanding cage effects in the $\mathrm{N}$-alkane conversion on zeolites. J Catal 237:278-290

33. Catlow CRA (1992) Modelling of structure and reactivity in zeolites. Academic Press, Cambridge

34. Catlow CRA, Smit B, van Santen R (2004) Computer modeling of microporous materials. Elsevier, Amsterdam

35. Smit B, Maesen TL (2008) Molecular simulations of zeolites: adsorption, diffusion, and shape selectivity. Chem Rev 108:4125-4184
36. Chempath S, Snurr RQ, Low JJ (2004) Molecular modeling of binary liquid-phase adsorption of aromatics in Silicalite. AIChE J 50:463-469

37. Pophale R, Daeyaert F, Deem MW (2013) Computational prediction of chemically synthesizable organic structure directing agents for zeolites. J Mater Chem 1:6750-6760

38. Bai P, Siepmann JI, Deem MW (2013) Adsorption of glucose into zeolite beta from aqueous solution. AIChE J 59:3523-3529

39. Fatouros DG, Douroumis D, Nikolakis V, Ntais S, Moschovi AM, Trivedi V, Khima B, Roldo M, Nazar H, Cox PA (2011) In vitro and in Silico investigations of drug delivery via zeolite BEA. J Mater Chem 21:7789-7794

40. Spanakis M, Bouropoulos N, Theodoropoulos D, Sygellou L, Ewart S, Moschovi AM, Siokou A, Niopas I, Kachrimanis K, Nikolakis V (2014) Controlled release of 5-fluorouracil from microporous zeolites. Nanomedicine: nanotechnology. Biol Med 10:197-205

41. Baerlocher C, McCusker LB, Olson DH (2007) Atlas of zeolite framework types. Elsevier, Amsterdam

42. Buser HR, Poiger T, Müller MD (1998) Occurrence and fate of the pharmaceutical drug diclofenac in surface waters: rapid photodegradation in a lake. Environ Sci Technol 32:3449-3456

43. Kimosop SJ, Getenga Z, Orata F, Okello V, Cheruiyot J (2026) Residue levels and discharge loads of antibiotics in wastewater treatment plants (WWTPS), hospital lagoons, and rivers within lake Victoria basin, Kenya. Environ Monit Assess 188:532

44. Kiselev AV, Bezus AG, Lopatkin AA, Du PQ (1978) Molecular statistical calculation of the thermodynamic adsorption characteristics of zeolites using the atom-atom approximation. Part 1-Adsorption of methane by Zeolite Nax. J Chem Soc Faraday Trans 2 Mol Chem Phys 74:367-379

45. Metropolis N, Rosenbluth AW, Rosenbluth MN, Teller AH, Teller E (1953) Equation of state calculations by fast computing machines. J Chem Phys 21(6):1087-1092

46. Kirkpatrick JSCDG, Vecchi MP (1983) Optimization by simulated annealing. Science 220:671-680

47. Mayo SL, Olafson BD, Goddard WA (1990) Dreiding: a generic force field for molecular simulations. J Phys Chem 94:8897-8909

48. Kim S, Chen J, Cheng T, Gindulyte A, He J, He S, Li Q, Shoemaker BA, Thiessen PA, Yu B (2019) Update: improved access to chemical data. Nucl Acids Res 47:D1102-D1109

49. Biovia DS (2017) San Diego: Dassault systems

50. Delley B (1990) An all-electron numerical method for solving the local density functional for polyatomic molecules. J Chem Phys 92:508-517

51. Delley B (2000) From molecules to solids with the $\mathrm{Dmol}^{3}$ approach. J Chem Phys 113:7756-7764

52. Von Barth U, Hedin L (1972) A local exchange-correlation potential for the spin polarized case-I. J Phys C: Solid State Phys 5:1629

53. Stefaniu A, Pintilie $L$ (2018) Molecular descriptors and properties of organic molecules. Symm (Group Theory) Math Treat Chem 161

54. Mebi CA (2011) DFT study on structure, electronic properties, and reactivity of cis-isomers of $\left[\left(\mathrm{NC}_{5} \mathrm{H}_{4}-\mathrm{S}\right)_{2} \mathrm{Fe}(\mathrm{CO})_{2}\right]$. J Chem Sci 123(5):727-731

55. Giles $\mathrm{CH}$, Huitson DSA (1974) A general treatment and classification of the solute adsorption isotherm-l. Theor J Colloid Interf Sci 47:755-765

56. Martucci A, Pasti L, Marchetti N, Cavazzini A, Dondi F, Alberti A (2012) Adsorption of pharmaceuticals from aqueous solutions on synthetic zeolites. Microporous Mesoporous Mater 148:174-183 
57. Pham TH, Lee BK, Kim J, Lee $\mathrm{CH}$ (2016) Enhancement of $\mathrm{CO}_{2}$ capture by using synthesized Nano-Zeolite. J Taiwan Inst Chem Eng 64:220-226

58. Schenk M, Smit B, Vlugt T, Maesen TL (2001) Shape selectivity in Alkane hydroconversion. Angew Chem Int Edn Eng 40:736-738
59. Hof F, Nuckolls C, Rebek J (2000) Diversity and selection in selfassembled tetrameric capsules. J Am Chem Soc 122:4251-4252

Publisher's Note Springer Nature remains neutral with regard to jurisdictional claims in published maps and institutional affiliations. 